NASZA DERMATOLOGIA Online OUR DERMATOLOGY Online

Source of Support: Nil

Competing Interests:

None

\section{A CASE OF PYOGENIC GRANULOMA AT AN UNUSUAL LOCATION}

\author{
Yugandar Inakanti, Akshaya Nagaraja, Srilakshmi Peddireddy, \\ Vijayshankar Metikurke
}

Department of Dermatology, Venerology and Leprosy, P.E.S. Institute of Medical Sciences and Research, Kuppam, AP, India

Corresponding author: Dr. Yugandar Inakanti

dryugandar@gmail.com

\begin{abstract}
Pyogenic granulomas are common, acquired, benign vascular lesions of the skin and mucousmembranes that can develop both spontaneously and traumatically. Pyogenic Granuloma more commonly involves Gingiva (75\% of all the cases). An extragingival occurrence of pyogenic granuloma is rare. We present an unique case of a male patient aged 24 years affected by Pyogenic Granuloma of urethral meatus. Although penile pyogenic granulomas have previously been observed over glans penis, prepuce and shaft of penis, there are no reports affecting meatus.
\end{abstract}

Key words: Benign lesions; Botromycosis; Pyogenic Granuloma; Urethral Meatus

\section{Introduction}

Pyogenic Granuloma described first byHullihen,is a benign, non-neoplastic, mucocutaneous lesion. The name, "pyogenic granuloma" is a misnomer,since this condition is not associated with pus and as it does not represent a Granuloma histologically. PG is thought to represent an exuberant tissue response to a local irritation or trauma [1].

\section{Case Report}

A 24 years old male patient reported to our department with the complaints of a growth over the glans penis near meatus of six months duration, sudden in onset, had gradually increased to the present size and was associated with spotting.

The unmarried patient denied genital trauma and history of sexual intercourse during the preceding 6 months. The physical examinations were with in normal limits. No lymphadenopathy observed. On systemic examination no abnormality was revealed. Clinically there was no evidence of sexually transmitted diseases. Following investigations of complete blood counts, ESR, chest radiography, HIV, VDRL and mantoux test were within normal limits.

The clinical examination revealed a small, erythematous papuleover the glans penis at the meatus, measuring about $0.5 \mathrm{~cm}$ in diameter (Fig. 1, 2). The lesion was soft in consistency and non tender, with minimal bleeding.

A differential diagnosis of Pyogenic Granuloma, Cherry angioma, Urethral caruncle Angiokeratoma, genital wart and
Pyoderma gangrenosum [6] was considered.

Because of its small size, an excisional biopsy was done and submitted for histological examination.

The histopathologic examination showed an intact epidemis. The sub epithelial region showed many thin walled varying sized capillaries, few dilated and filled with RBC's. The intervening stroma showed infiltrate predominately of neutrophils, occasional areas showing hemosiderin deposits (Fig. 3 A, B).

Histology confirmed the diagnosis of Pyogenic Granuloma.

\section{Discussion}

Pyogenic Granuloma is a vascular nodule that develops rapidly, often at the site of a recent injury, and is composed of a lobular proliferation of capillaries in a loose stroma [2].

In 1844, Hullihen described the first case of pyogenic granuloma. In 1897 Pyogenic granuloma in man was described as "botryomycosis hominis." Hartzell in 1904 is credited with giving the current term of "pyogenic granuloma" or "granuloma pyogenicum." It was also called as Crocker and Hartzell's disease. Angelopoulos histologically described it as "hemangiomatous granuloma" due to the presence of numerous blood vessels and the inflammatory nature of the lesion [1]. Gingiva is the predominant site followed by lips and hard plate. Oral pyogenic granuloma is more common in females, in second and fifth decades due to the vascular effects of the female hormones [1]. 


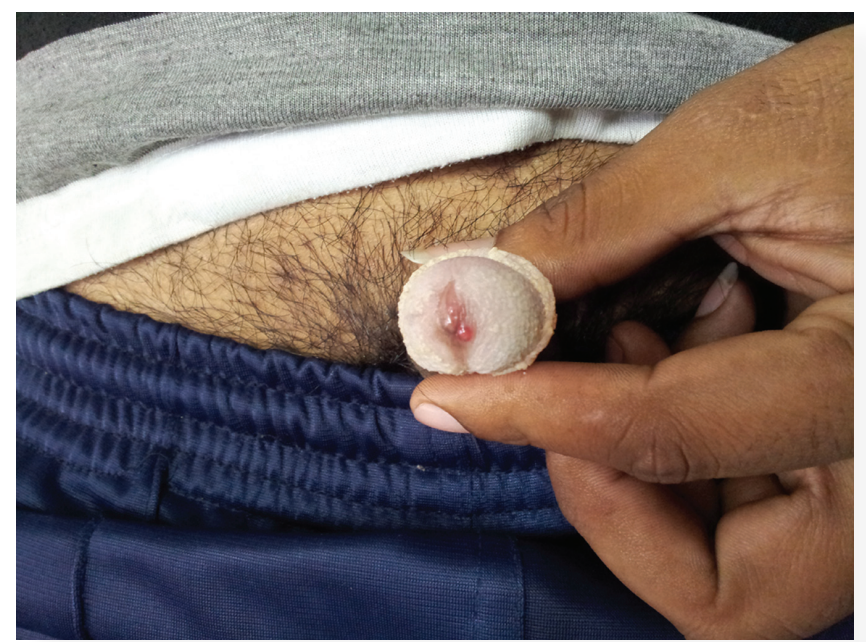

Figure 1. Glistening, red papule over urethral meatus with poor hygienic glans penis.

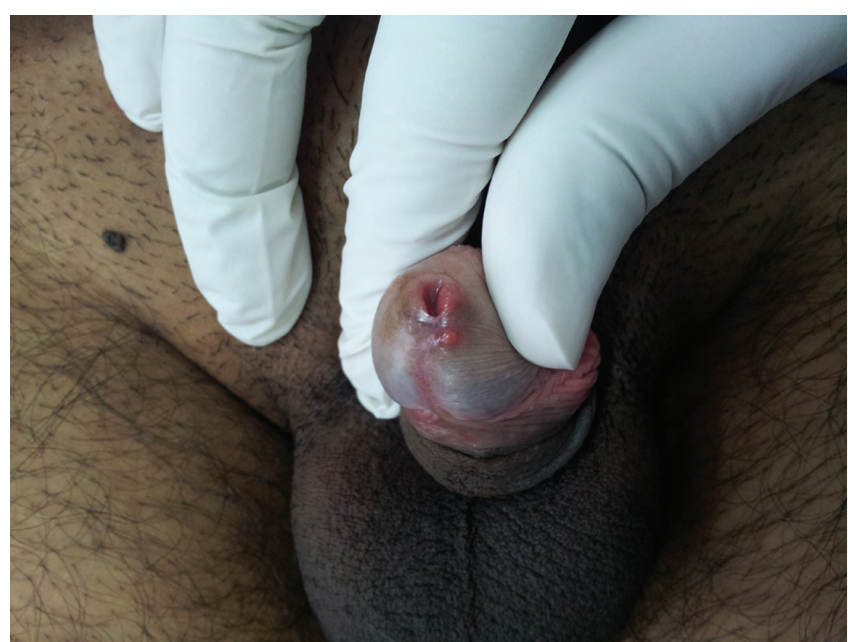

Figure 2. Small Erythematous papule, $5 \mathrm{~mm}$ in size over urethral meatus.
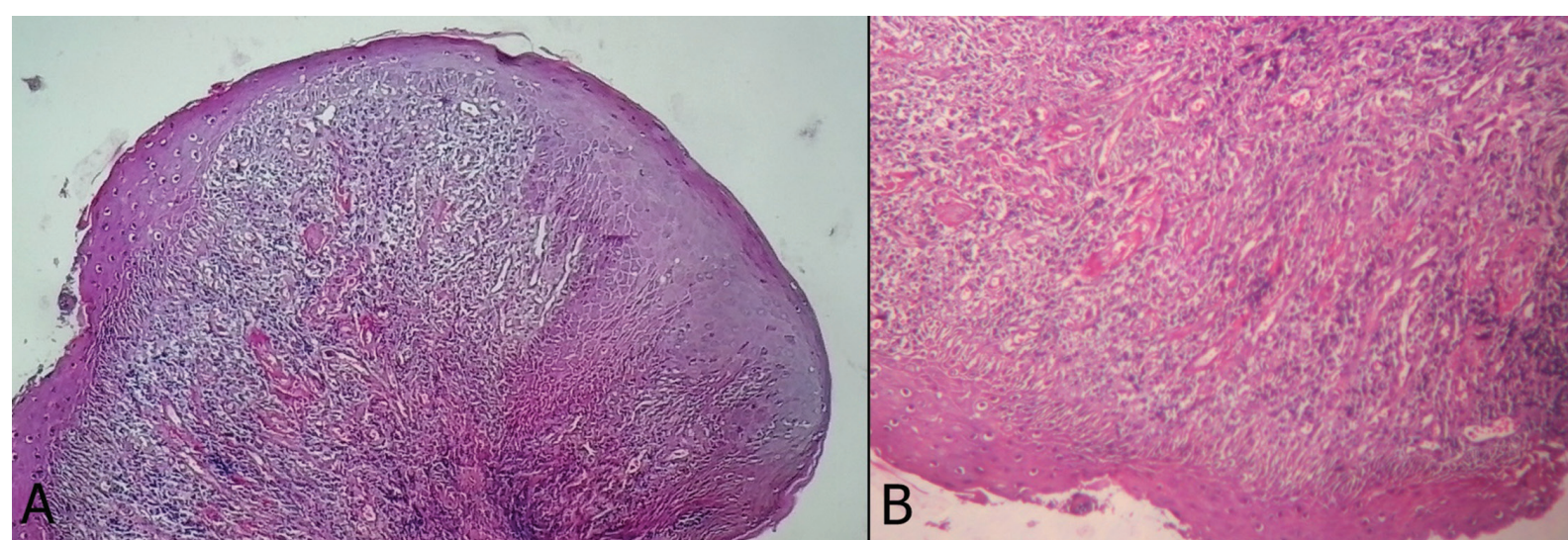

Figure $3 \mathrm{~A}$ and B. Scanner view Shows nodular configuration underneath epidermis. On High power magnified view shows mild hyperkeratotic, Parakeratotic, irregular acanthotic epidermis. Sub epidermal zone shows different sizes of dilated blood vessels filled with RBC's and endothelial cell lining walls. The stroma shows neutrophils infiltrate predominantly. Foci of Haemosiderin deposits shown.
Clinically, pyogenic granulomas begin as small red papules that rapidly increase in size ranging from a few millimeters to several centimeters. Pyogenic granulomas may have an initial period of rapid growth, followed by stabilization and occasionally regression [3].

We present here an unmarried male patient aged 24yrs, presented with a small erythematous papule with sessile base over meatus of glans penis with occasionalspotting. He denied history of genital trauma.

Clinically we considered adifferential diagnosis of Pyogenic Granuloma, urethral prolapse, cherry angioma, urethral caruncle, angiokeratoma,genital warts and pyoderma gangranosum of penis [4].

The histological examination showed an intact epidemis. The sub epithelial region showed many thin walled varying sized capillaries, few dilated and filled with RBC's. The intervening stroma is showing infiltrate predominately by neutrophils, occasional areas showing hemosiderin deposits.

The Histopathology of Pyogenic Granuloma shows a angiomatous tissue with endothelial cell proliferation, inflammatory cell infiltrate is seen in the form of few neutrophils, lymphocytes and plasma cells covered by parakeratinized epithelium [5].

A literature scan revealed a few cases of Pyogenic granuloma involving the shaft of penis [6] andprepuce of glans penis [79]. Literature search (using Medline) has revealed no previous reports of Pyogenic granuloma involving the meatus of glans penis. This is the first case report of Pyogenic Granuloma involving the urethral meatus.

\section{Conclusion}

Pyogenic granuloma is a common lesion of the skin and oral cavity, especially the gingiva. This case report emphasizes that the diagnosis of a penile pyogenic granuloma is complex and leads the dermatologist to consider distinct lesions with its myriad etiologies, clinical features, histological presentations and treatment modalities. We call attention to the uncommon location of Pyogenic Granuloma over meatus. Surgical excision is a safe method for diagnosis and treatment of Pyogenic Granuloma over meatus of glans penis. 


\section{Acknowledgement}

We gratefully acknowledge the help of,

1. Principal, Pesimsr, Kuppam.

2. Professor and Hod, Department of DVL, Pesimsr, Kuppam.

3. Professor, Department of Pathology, Pesimsr, Kuppam.

\section{REFERENCES}

1. Kamala KA, Ashok L, Sujatha GP. Pyogenic Granuloma on Upper Labial Mucosa: A Case Report. J Clin Diagn Res. 2013;7:1244-46.

2. Calonje E. Soft Tissue tumours and tumour like conditions In: Rooks Burns T, Breathnach S, Cox N, Griffiths C, editors. Rooks textbook of Dermatology.8th edition, vol 3 Oxford:Blackwell;2010. p56.25.
3. Ravi V, Jacob M, Sivakumar A. Pyogenic granuloma of labial mucosa: A misnomer in an anomolous site. J Pharma Bioallied Sci. 2012;4:194-6.

4. Kim TE, Oh SY, Myung SCh. Pyoderma Gangranosum of the Penis. J Korean Med Sci. 2009;24:1200-2.

5. Gomes SR, Shakir QJ, Thaker PV, Tavadia JK. Pyogenic granuloma of the gingiva: A misnomer? - A case report and review of literature. J Indian Soc Periodontol. 2013;17:514-9.

6. Bhaduri S, Fisk PG, Johnston G. Pyogenic granuloma of the penisdon't squeeze them. Sex Transm Inf. 2000;76:217.

7. Walzman M, Kundu A, Fraser I. Pyogenic granuloma of the penis a rare entity? Genitourin Med. 1995;71:43-4.

8. Tomasini C, Puiatti P, Bernengo MG. Multiple pyogenic granuloma of the penis. Sex Transm Inf. 1998;74:221-2.

9. Spinelli C, Di Giacomo M, Bertocchini A. Multiple pyogenic granuloma of the penis in a four-year-old child: a case report. Cases J. 2009;2:7831.

Copyright by Inakanti Yugandar, et al. This is an open access article distributed under the terms of the Creative Commons Attribution License, which permits unrestricted use, distribution, and reproduction in any medium, provided the original author and source are credited. 